\title{
Kinerja Pegawai Ditinjau Dari Perilaku Cyberloafing Dan Komitmen Organisasi
}

\author{
Rika Wahyuni, Hadi Irfani, Rina Mariana \\ Fakultas Ekonomi dan Bisnis, Fakultas Psikologi, Universitas Putra Indonesia "YPTK" \\ Padang, Indonesia \\ e-mail:rikawahyuni070685@gmail.com, hadi.irfani.st@gmail.com, rinadeded@gmail.com
}

\begin{abstract}
The aim of this study was to determine the influence cyberloafing behavior and organizational commitmenton employee performance. This research is a quantitative research with a descriptive approach, respondents surveyed in this study amounted to 101 employees of the Padang City Department of Educationby saturated sampling technique.Then carried out analysis to the data obtained by using multiple linear regression analysis. The results found: (1) cyberloafing behavior has a negative and significant effect on employee performance, (2) organizational commitment has a positive and significant effect on employee performance and (3) cyberloafing behavior and organizational commitment simultaneously has a significant effect on employee performance. The contribution of cyberloafing behavior and organizational commitment on employee performance amounted to $65.2 \%$. Where as the remainder about $34.8 \%$ described by other variable is not used within this research.
\end{abstract}

Keywords: cyberloafing behavior, organizational commitment, employee performance

\begin{abstract}
Abstrak
Tujuan dari penelitian ini adalah untuk mengetahui pengaruh perilaku cyberloafing dan komitmen organisasi terhadap kinerja pegawai. Penelitian ini merupakan penelitian kuantitatif dengan pendekatan deskriptif, responden yang diteliti dalam penelitian ini berjumlah 101 orang pegawai Dinas Pendidikan Kota Padang ditentukan dengan teknik sampling jenuh. Kemudian dilakukan analisis terhadap data yang diperoleh dengan menggunakan analisis regresi linear berganda. Hasil penelitian menemukan: (1) perilaku cyberloafing berpengaruh negatif dan signifikan terhadap kinerja pegawai, (2) komitmen organisasi berpengaruh positif dan signifikan terhadap kinerja pegawai dan (3) perilaku cyberloafing dan komitmen organisasi secara simultan berpengaruh signifikan terhadap kinerja pegawai. Kontribusi perilaku cyberloafing dan komitmen organisasi terhadap kinerja pegawai sebesar $65,2 \%$. Sedangkan sisanya $34,8 \%$ dijelaskan oleh variabel lain yang tidak diteliti dalam penelitian ini.
\end{abstract}

Kata kunci: perilaku cyberloafing, komitmen organisasi, kinerja pegawai

\section{Pendahuluan}

Terwujudnya pemerintahan yang baik (Good Governance) merupakan tuntutan agar manajemen pemerintahan dan pembangunan dapat terselenggara dengan berdayaguna dan berhasil guna, maka dalam rangka itu perlu adanya kinerja pegawai yang optimal sehingga berdampak positif bagi pelayanan publik dan kinerja instansi dalam pencapaian tujuan organisasi. Fattah (2017) mendefinisikan kinerja pegawai sebagai unjuk kerja pegawai dalam melaksanakan keseluruhan tugastugas yang menjadi tanggungjawabnya. Tugas tersebut berdasarkan keberhasilan pegawai yang sudah menjadi ketetapan organisasi. Artinya, keberhasilan organisasi tergantung pada kualitas kinerja sumber daya manusia yang ada di dalamnya. Pemanfaatan internet membantu proses kerja pegawai menjadi lebih cepat dalam memenuhi tugas dan fungsinya sebagai pelayanan masyarakat. Sejalan dengan pendapat Oetomo dalam Sofyanty (2019) bahwa pegawai dan pimpinan organisasi memanfaatkan komputer yang terkoneksi dengan internet saat mengerjakan tugasnya dengan aplikasi atau sistem informasi, dimana tujuannya yaitu meningkatkan dan memperlancar aliran informasi yang menjadi nadi kehidupan organisasi. Tanpa informasi, pimpinan kesulitan mengetahui kondisi obyektif organisasi. Jadi, pimpinan akan dapat menjalankan siklus manajerial yaitu perencanaan, pengorganisasian, kepemimpinan dan pengendalian secara sehat. Pimpinan juga dapat membuat keputusan dengan cepat dan menyusun strategi jitu untuk meningkatkan kemampuan organisasi. Tingginya pemanfaatan internet untuk keperluan aplikasi atau akses informasi bagi pegawai tidak menutup kemungkinan pegawai memanfaatkannya untuk kegiatan atau hal-hal yang tidak ada

Diterima Redaksi : 25-04-2020 | Selesai Revisi : 07-05-2020 | Diterbitkan Online : 01-06-2020 
kaitannya dengan pekerjaan atau dikenal dengan istilah perilaku cyberloafing. Lim dan Chen (2012) menyatakan bahwa perilaku cyberloafing pegawai dapat dilihat dari penggunaan akses internet ditempat kerja untuk keperluan pribadi selama jam kerja dan menghabiskan rata-rata 51 menit per hari untuk cyberloafing. Dari beberapa peneliti terdahulu yang mengamati keterkaitan antara cyberloafing dengan kinerja pegawai diantaranya dilakukan oleh Olajide, dkk (2018), Lim dan Chen (2012), AlShuaibi, dkk (2013) dan Sitorus, dkk (2019). Hasil penelitian menunjukkan pengaruh perilaku cyberloafing terhadap kinerja pegawai masih belum konsisten sehingga perlu dilakukan penelitian lanjutan untuk mendapatkan kesimpulan. Faktor komitmen organisasi juga salah satu hal yang dapat mempengaruhi kinerja pegawai. Pemahaman tentang arti komitmen organisasi sangat penting bagi pegawai agar tercipta kondisi kerja yang kondusif sehingga organisasi dapat berjalan secara efisien dan efektif. Kaswan (2012) menyatakan komitmen organisasi adalah sikap yang merefleksikan loyalitas pegawai pada organisasi dan proses berkelanjutan dimana anggota organisasi mengekspresikan perhatiannya terhadap organisasi dan keberhasilan serta kemajuan yang berkelanjutan. Respatiningsih dan Sudirjo (2015) menyatakan bahwa komitmen organisasi berpengaruh signifikan terhadap kinerja pegawai. Penelitian yang dilakukan oleh Okto, dkk (2014) menemukan bahwa adanya pengaruh signifikan komitmen organisasional terhadap kinerja pegawai. Namun, tidak konsisten dengan penelitian Carmeli dan Freund (2004) menemukan bahwa komitmenorganisasi tidak berpengaruh terhadapkinerja pegawai. Studi ini dilakukan di Dinas Pendidikan Kota Padang. Sebagaimana diketahui, Dinas Pendidikan Kota Padang adalah Satuan Kerja Perangkat Daerah (SKPD) di Kota Padang yang mempunyai tugas membantu Kepala Daerah dalam penyelenggaraan pemerintahan daerah di bidang pendidikan. Dinas Pendidikan Kota Padang diharapkan mampu memberikan kinerja yang baik untuk memberikan pelayanan dalam bidang pendidikan. Untuk memberikan pelayanan yang maksimal, Dinas Pendidikan Kota Padang menyediakan internet agar mempermudah proses kerja pegawai. Dari hasil survey di lapangan, masih ditemukan pegawai yang tidak memanfaatkan internet untuk kepentingan pekerjaan, tetapi digunakan untuk kepentingan pribadi misalkan sebagai tujuan hiburan, hanya untuk bermain game, browsing google dengan informasi selebritis, kemudian juga membuka jejaring sosial seperti facebook, twitter dan lain-lain. Perilaku cyberloafing yang ditampilkan pegawai dikategorikan sebagai perilaku indisipliner, terbaginya konsentrasi pegawai antara pekerjaan dengan perilaku cyberloafing berimbas pada menumpuknya pekerjaan, produktivitas kerja yang rendah, kualitas kerja yang buruk, dapat mengganggu kelancaran proses kerja dan lambatnya pelayanan publik sehingga berdampak terhadap penurunan kinerja pegawai. Kondisi ini juga memperlihatkan bahwa masih rendahnya komitmen pegawai terhadap organisasi yang membuat hasil kerja pegawai tidak optimal. Adanya permasalahan di atas dan ditemukannya research gap atau hasil temuan penelitian terdahulu yang berbeda-beda membuat peneliti tertarik mengambil judul penelitian "Kinerja Pegawai Ditinjau Dari Perilaku Cyberloafing dan Komitmen Organisasi”.

\subsection{Kinerja Pegawai}

Sulaksono (2019) mendefinifikan kinerja pegawai adalah penilaian yang dilakukan secara sistematis untuk mengetahui hasil pekerjaan pegawai dan kinerja organisasi. Pendapat Fattah (2017) menyatakan kinerja pegawai sebagai unjuk kerja pegawai dalam melaksanakan keseluruhan tugas-tugas yang menjadi tanggungjawabnya. Tugas tersebut berdasarkan keberhasilan pegawai yang sudah menjadi ketetapan organisasi. Pendapat lainnya dikemukakan oleh Sinambela (2016) mendefinisikan kinerja sebagai kemampuan pegawai dalam melakukan sesuatu keahlian tertentu dan seberapa jauh kemampuan mereka dalam melaksanakan tugas yang dibebankan kepadanya. Robert dan Bacal dalam Kaswan (2012) menjelaskan bahwa kinerja merupakan tingkat kontribusi yang diberikan pegawai terhadap tujuan pekerjaannya atau unit kerja dan organisasi sebagai hasil perilakunya dan aplikasi dari keterampilan, kemampuan dan pengetahuannya. Indikator kinerja pegawai diukur berdasarkan teori Mathis dan Jackson (2015) yaitu quantity of work (kuantitas), qualityof work (kualitas), timeline of work (ketepatan waktu), attendance (kehadiran) dan ability to cooporate (kerjasama).

\subsection{Perilaku Cyberloafing}

Istilah cyberloafing secara singkat digambarkan sebagai penggunaan pribadi internet di lingkungan kerja (Lim dalam Olajide, 2018). Menurut Lim, dkk dalam Sitorus, dkk (2019) menyebutkan bahwa cyberloafing adalah segala tindakan disengaja karyawan menggunakan akses internet perusahaan 
selama jam kerja untuk browsing situs yang tidak berkaitan dengan pekerjaan untuk tujuan pribadi dan aktivitas memeriksa (termasuk menerima dan mengirim) pribadi sebagai penyalahgunaan internet. Pendapat Herdiati, dkk (2015) cyberloafing diartikan sebagai penggunaan internet pada saat jam kerja dengan menggunakan internet organisasi. Sedangkan pendapat Blanchard dan Henle (2008) cyberloafing adalah aktivitas mengakses internet saat jam kerja melalui berbagai jenis perangkat seperti komputer, handphone dan tablet untuk tujuan pribadi pada pegawaisaat jam kerja. Indikator perilaku cyberloafing diukur menggunakan teori Lim dan Chen (2009) yaitu browsing activities dan emailing activities.

\subsection{Komitmen Organisasi}

Pendapat Meyer dan Allen dalam Yusuf dan Syarif (2018) komitmen organisasi adalah konstruk psikologis sebagai karakteristik hubungan anggota organisasi dengan organisasinya, serta berimplikasi terhadap keputusan individu untuk melanjutkan keberadaannya sebagai anggota dalam organisasi. Sedangkan Yusuf dan Syarif (2018) mengemukakan komitmen organisasi sebagai sikap loyalitas pegawai terhadap organisasi dengan cara tetap bertahan dalam organisasi, membantu mencapai tujuan organisasi, dan tidak memiliki keinginan untuk meninggalkan organisasi dengan alasan apapun. Menurut Kreitner dan Kinicki (2014) komitmen organisasi adalah tingkatan dimana pegawai mampu mengenali organsiasinya dan terikat pada tujuan-tujuan organisasi tersebut. Ini adalah sikap kerja yang penting karena orang-orang yang memiliki komitmen diharapkan bisa menunjukkan kesediaan untuk bekerja lebih keras demi mencapai tujuan organisasi dan memiliki hasrat yang lebih besar untuk tetap bekerja di suatu organisasi. Pendapat lainnya dikemukakan oleh Moorhead dan Griffin (2013) menyatakan bahwa komitmen organisasi adalah identifikasi dan ikatan seseorang pada sebuah organisai. Indikator komitmen organisasi yang digunakan dalam penelitian menurut teori Meyer dan Allen dalam Yusuf dan Syarif (2018) terdiri dari komitmen afektif (affective commitment), komitmen normatif (normative commitment) dan komitmen berkelanjutan (continuance commitment).

\section{Metode Penelitian}

Penelitian ini merupakan penelitian kuantitatif dengan pendekatan deskriptif. Variabel independen yaitu Perilaku Cyberloafing (X1), Komitmen Organisasi(X2), kemudian variabel dependen dalam penelitian ini yaitu Kinerja Pegawai (Y). Populasi yaitu seluruh pegawai Dinas Pendidikan Kota Padang. Jumlah sampel yang diambil sebanyak 110 orang ditentukan dengan teknik sampling jenuh. Untuk mendapatkan hasil dari penelitian yang dilakukan dan untuk menjawab hipotesis dilakuan uji analisis regresi linear berganda, uji t, uji F dan uji determinasi.

\section{Hasil dan Pembahasan}

Peneliti menyebarkan 110 kuesioner yang terdiri dari variabel perilaku cyberloafing, komitmen organisasi, kinerja pegawai dan meminta kesediaan kepada pegawai Dinas Pendidikan Kota Padang tersebut untuk mengisi kuesioner dan kemudian menjelaskan cara pengisian kuesioner dengan cara memberikan kuesioner secara langsung. Sebelum pengisian angket dilakukan, peneliti terlebih dahulu memberitahukan petunjuk pengisian dengan singkat dan jelas.

\subsection{Hasil}

Untuk mengetahui seberapa besar koefisien regresi dari masing-masing variabel independent dan bagaimana arah pengaruhnya terhadap variabel dependent, dapat dilihat dari analisis data regresi berganda yang diperoleh dengan menggunakan program SPSS Versi 23 seperti pada tabel berikut ini:

\begin{tabular}{lccc}
\multicolumn{4}{c}{ Tabel 1. Hasil Persamaan Regresi Linear Berganda } \\
\multicolumn{1}{c}{ Model } & B & t & Sig. \\
\hline (Constant) & 28,224 & 7,899 & 0,000 \\
Perilaku Cyberloafing & & & 0,000 \\
Komitmen Organisasi & $-0,325$ & $-3,723$ & 0,000 \\
\hline Sumber: Olah data output SPSS 23, 2020 & 0,498 & 9,208 &
\end{tabular}


Berdasarkan pengolahan data tabel 1 maka dapat diperoleh persamaan regresi sebagai berikut:

$$
Y=28,224-0,325 X_{1}+0,498 X_{2}
$$

Persamaan regresi linier berganda di atas dapat diartikan, yaitu: (1) Nilai konstanta sebesar 28,224 menyatakan bahwa jika tidak ada kenaikan nilai dari variabel perilaku cyberloafing dan komitmen organisasi maka nilai dari kinerja pegawai adalah 28,224. (2) Nilai koefisien regresi perilaku cyberloafing bersifat negatif sebesar $-0,325$, artinya variabel perilaku cyberloafing memiliki hubungan berlawanan arah dengan kinerja pegawai dan setiap penambahan satu satuan perilaku cyberloafing akan berpengaruh terhadap menurunnya kinerja pegawai Dinas Pendidikan Kota Padang (Y) sebesar 0,325 dan (3) Nilai koefisien regresi komitmen organisasi bersifat positif sebesar 0,498 , artinya variabel komitmen organisasi memiliki hubungan searah dengan kinerja pegawai dan setiap pertambahan satu satuan komitmen organisasi akan berpengaruh terhadap meningkatnya kinerja pegawai Dinas Pendidikan Kota Padang (Y) sebesar 0,498.

\begin{tabular}{lccc}
\multicolumn{1}{c}{ Tabel 2. Hasil Uji t } \\
\hline \multicolumn{1}{c}{ Model } & t & Sig. & Keterangan \\
\hline (Constant) & 7,899 & 0,000 & Berpengaruh \\
Perilaku Cyberloafing & $-3,723$ & 0,000 & Berpengaruh \\
Komitmen Organisasi & 9,208 & 0,000 & Berpengaruh \\
\hline Sumber: Olah data output SPSS 23, 2020 & &
\end{tabular}

Hasil untuk uji t dapat dilihat pada tabel 2 di atas, dapat dijabarkan, yaitu: (1) nilai t hitung yang diperoleh variabel perilaku cyberloafing adalah $-3,723$ dengan nilai signifikan 0,000. Maka dapat disimpulkan bahwa t hitung > t tabel serta Sig. $\alpha<0,05$ yaitu $-3,723>1,984$ serta 0,000 $<0,05$ yang berarti $\mathrm{H}_{0}$ ditolak dan $\mathrm{H}_{1}$ diterima. Dengan demikian variabel perilaku cyberloafing berpengaruh signifikan terhadap kinerja pegawai Dinas Pendidikan Kota Padang. (2) nilai t hitung yang diperoleh variabel komitmen organisasi adalah 9,208 dengan nilai signifikan 0,000. Maka dapat disimpulkan bahwa thitung > ttabel serta Sig. $\alpha<0,05$ yaitu 9,208 $>1,984$ serta $0,000<0,05$ yang berartiH $\mathrm{H}_{0}$ ditolak dan $\mathrm{H}_{2}$ diterima. Dengan demikian variabel komitmen organisasi berpengaruh signifikan terhadap kinerja pegawai Dinas Pendidikan Kota Padang.

\begin{tabular}{|c|c|c|c|}
\hline Model & $\mathbf{F}$ & Sig & Keterangan \\
\hline Regression & 94,482 & 0,000 & Berpengaruh \\
\hline $\begin{array}{l}\text { Residual } \\
\text { Total }\end{array}$ & & & \\
\hline
\end{tabular}

Nilai F hitung yang diperoleh dari tabel 3 di atas adalah sebesar 94,482 dengan nilai signifikan 0,000. Maka dapat disimpulkan bahwa F hitung $>$ F tabel serta Sig. $\alpha>0,05$. Berdasarkan kriteria tersebut, terlihat bahwa 94,483 > 3,93 serta 0,000 < 0,05 yang berarti $\mathrm{H}_{0}$ ditolak dan $\mathrm{H}_{3}$ diterima. Hal ini berarti perilaku cyberloafing dan komitmen organisasi secara simultan berpengaruh signifikan terhadap kinerja pegawai Dinas Pendidikan Kota Padang.

Tabel 4. Hasil Uji Koefisien Determinasi

\begin{tabular}{|c|c|c|c|c|}
\hline Model & $\mathbf{R}$ & R Square & Adjusted R Square & Std. Error of the Estimate \\
\hline 1 &, $811^{\mathrm{a}}$ &, 658 & ,652 & 3,059 \\
\hline
\end{tabular}

Tabel 4 menunjukan bahwa nilai AdjustedR Square $=0,652$ berarti kontribusi variabel perilaku cyberloafing dan komitmen organisasi terhadap kinerja pegawai Dinas Pendidikan Kota Padang sebesar 65,2\% sedangkan sisanya 34,8\% dijelaskan oleh variabel lain yang tidak diteliti dalam penelitian ini seperti motivasi kerja, stres kerja, beban kerja, kapabilitas dan lain sebagainya.

\subsection{Pembahasan}

Hasil uji hipotesis pertama $\left(\mathrm{H}_{1}\right)$ menunjukkan nilai koefisien regresi sebesar -0,325 dengan nilai signifikansi yaitu $0,000<0,05$. Hal ini berarti perilaku cyberloafing berpengaruh signifikan terhadap kinerja pegawai Dinas Pendidikan Kota Padang dengan arah negatif. Artinya, perilaku cyberloafing yang tinggi menyebabkan menurunnya kinerja pegawai, sebaliknya perilaku cyberloafing yang rendah, 
menyebabkan meningkatnya kinerja pegawai. Lim dan Chen (2012) menyatakan bahwa aktivitas penjelajahan memiliki dampak positif pada emosi pegawai saat melakukan aktivitas email dan memiliki dampak negatif terhadap kinerja pegawai. Penelitian Al-Shuaibi, dkk (2013) menyatakan penilaian kinerja dan kemajuan karir ditemukan memprediksi secara negatif cyberloafing. Hasil ini tidak konsisten dengan penelitian Sitorus, dkk (2019) bahwa cyberloafing berpengaruh tidak signifikan positif terhadap kinerja karyawan. Dari hasil uji hipotesis kedua $\left(\mathrm{H}_{2}\right)$ menunjukkan nilai koefisien regresi sebesar 0,498 dengan nilai signifikansi yaitu $0,000<0,05$. Hal ini berarti komitmen organisasi berpengaruh signifikan terhadap kinerja pegawai Dinas Pendidikan Kota Padang dengan arah positif. Artinya, semakin tinggi komitmen organisasi, maka kinerja pegawai semakin meningkat, sebaliknya semakin rendah komitmen organisasi, maka kinerja pegawai semakin menurun. Khan, dkk dalam Pratama dan Dihan (2017) menyatakan bahwa komitmen dari pegawai terhadap organisasi dapat menjadi instrumen penting untuk meningkatkan kinerja dari pegawai tersebut. Pendapat ini sejalan dengan penelitian Sitorus dan Soesatyo (2014) menyatakan bahwa komitmen organisasi berpengaruh signifikan terhadap kinerja pegawai. Hasil ini juga didukung oleh penelitian Sapitri (2016) bahwa komitmen organisasi berpengaruh positif dan signifikan terhadap kinerja karyawan. Namun penelitian ini tidak konsisten dengan penelitian Murty dan Hudiwinarsih (2014) yang mengatakan bahwa komitmen organisasi tidak berpengaruh signifikan terhadap kinerja karyawan. Hipotesis ketiga $\left(\mathrm{H}_{3}\right)$ dalam penelitian ini perilaku cyberloading dan komitmen organisasi secara simultan berpengaruh terhadap kinerja pegawai Dinas Pendidikan Kota Padang. Dari hasil pengujian didapat bahwa nilai sig. pada pengujian hipotesis ini lebih kecil dari nilai alpha $(0,05)$ yaitu $0,000<$ 0,05 . Begitu juga nilai $F$ hitung pada pengujian hipotesis ini lebih besar dibandingkan sengan nilai $F$ tabel yaitu 94,483 > 3,93 sehingga untuk hipotesis keempat (H3) diterima, yang berarti bahwa perilaku cyberloading dan komitmen organisasi secara simultan berpengaruh signifikan terhadap kinerja pegawai Dinas Pendidikan Kota Padang.

\section{Kesimpulan}

Dari hasil penelitan dan pembahasan yang telah dikemukanan di atas, maka dapat disimpulkan sebagai berikut: (1) Perilaku cyberloafing berpengaruh negatif dan signifikan terhadap kinerja pegawai Dinas Pendidikan Kota Padang. Perilaku cyberloafing yang tinggi menyebabkan menurunnya kinerja pegawai, sebaliknya perilaku cyberloafing yang rendah, menyebabkan meningkatnya kinerja pegawai. (2) Komitmen organisasi berpengaruh positif dan signifikan terhadap kinerja pegawai Dinas Pendidikan Kota Padang. Dengan demikian semakin tinggi komitmen organisasi, maka kinerja pegawai semakin meningkat, sebaliknya semakin rendah komitmen organisasi, maka kinerja pegawai semakin menurun. (3) Perilaku cyberloading dan komitmen organisasi secara simultan berpengaruh signifikan terhadap kinerja pegawai Dinas Pendidikan Kota Padang. Tinggi rendahnya kinerja pegawai dipengaruhi oleh perilaku cyberloading dan komitmen organisasi.

\section{Daftar Rujukan}

Fattah, H. 2017. Kepuasan Kerja dan Kinerja Pegawai, Budaya Organisasi, Perilaku Pemimpinan dan Efikasi Diri. Yogyakarta: Elmatera.

Sofyanty, D. 2019. Perilaku Cyberloafing Ditinjau Dari Psychological Capital dan Adversity Quotient. Jurnal Sekretari Dan Manajemen, 3(2), 2550-0791.

Lim, V. K. G., dan Chen, D. J. Q. 2012. Cyberloafing at The Workplace: Gain Or Drain On Work? Behaviour and Information Technology, 31(4), 343-353.

Olajide, O., Abdu, M., dan Abdul-Qadir, A. B. 2018. Effect Of Cyberloafing On Employee Performance Among Deposit Money Banks In Kaduna Metropolis. Journal of Arts, Management and Social Sciences (OJAMSS), 3(1), 27-37.

Al-Shuaibi, A., Shamsudin, F., dan Subramaniam, C. 2013. Do Human Resource Management Practices Matter in Reducing Cyberloafing At Work: Evidence From Jordan. Journal of WEI Business and Economics.

Sitorus, Riris, R., Nugrahaningsih, Hartanti., Yani, Ari, S., dan Gunawan, Gianita, U. 2019. Pengaruh Komitmen Organisasi dan Cyberloafing Terhadap Kinerja Karyawan Yang Dimoderasi Oleh Prosedur Kerja (SOP). Jurnal Media Manajemen Jasa, 7(2), 2502-3632.

Kaswan. 2012. Manajemen Sumber Daya Manusia untuk Keunggulan Bersaing Organisasi (Edisi 1). Yogyakarta: Graha Ilmu. 
Respatiningsih, Ida., dan Sudirjo, F. 2015. Pengaruh Komitmen Organisasi, Motivasi, Kapabilitas dan Kepuasan Kerja Terhadap Kinerja Pegawai. Jurnal Ilmiah UNTAG Semarang, 4(3).

Okto, Abrivianto, P., Bambang, Swasto., Hamidah, Nayati, U. 2014. Pengaruh Motivasi Kerja dan Komitmen Organisasional Terhadap Kinerja Karyawan (Studi Pada Karyawan Bagian HRD PT. Arthawena Sakti Gemilang Malang). Jurnal Administrasi Bisnis (JAB), 7(2).

Carmeli dan Freund. 2004. Work Commitment, Job Satisfaction and Job Performance: An Empirical Investigation. International Journal of Organization Theory and Behavior, 7(3), 289-309.

Sulaksono, H. 2019. Budaya Organisasi dan Kinerja. Yogyakarta : Deepublish.

Sinambela, Lijan, P. 2016. Manajemen Sumber Daya Manusia. Jakarta: PT. Bumi Aksara.

Mathis, R.L., dan Jackson, J. 2015. Manajemen Sumber Daya Manusia (Edisi 9). Jakarta: Salemba Empat. Herdiati, Meilisa, F., Sujoso, Anita, D.P., dan Hartanti, Ragil, I. 2015. Pengaruh Stresor Kerja dan Persepsi Sanksi Organisasi terhadap Perilaku Cyberloafing di Universitas Jember. E-Jurnal Pustaka Kesehatan, $3(1)$.

Blanchard, A,L., dan Henle. 2008. Correlates Of Different Forms Of Cyberloafing: The Role Of Norms And External Locus And Control. Computer in Human Behavior (Elsevier), 24(3), 1067-1084.

Lim, V.K.G., dan Chen, D. J. Q. 2009. Impact of Cyberloafing on Affect, Work depletion, Facilitation and Engagement. Conference Paper SIOP, 1-20.

Yusuf, Ria, M., dan Syarif, D. 2018. Komitmen Organisasi. Makassar: CV. Nas Media Pustaka.

Kreitner, Robert., dan Kinicki, A. 2014. Perilaku Organisasi (Edisi 9). Jakarta: Salemba Empat.

Moorhead, Gregory., dan Griffin, Ricky, W. 2013. Perilaku Organisasi: Manajemen Sumber Daya Manusia dan Organisasi (Edisi 9). Jakarta: Salemba Empat.

Pratama, Putra, M. A., dan Dihan, Fareshti, N. 2017. Pengaruh Komitmen Organisasional dan Disiplin Kerja Terhadap Kinerja Karyawan Melalui Kepuasan Kerja Sebagai Variabel Intervening. Jurnal Bisnis Teori Dan Implementasi, 8(2), 115-135.

Sitorus, Deo, S., dan Soesatyo, Y. 2014. Pengaruh Kemampuan, Motivasi Kerja dan Komitmen Organisasi terhadap Kinerja Karyawan. Jurnal Bisnis Dan Manajemen, 7(1), 45-52.

Sapitri, R. 2016. Pengaruh Komitmen Organisasi Terhadap Kinerja Karyawan Perusahaan Listrik Negara Area Pekanbaru. JOM Fisip, 3(2).

Murty, Windy, A., dan Hudiwinarsih, G. 2014. Pengaruh Kompensasi, Motivasi dan Komitmen Organisasional Terhadap Kinerja Karyawan Bagian Akuntansi (Studi Kasus Pada Perusahaan Manufaktur Di Surabaya). Jurnal Administrasi Bisnis (JAB), 7(2). 